\title{
Article \\ Development of Quaternary InAlGaN Barrier Layer for High Electron Mobility Transistor Structures
}

\author{
Justinas Jorudas ${ }^{1, *}\left(\mathbb{D}\right.$, Paweł Prystawko ${ }^{2}$, Artūr Šimukovič ${ }^{1}$, Ramūnas Aleksiejūnas ${ }^{3}$, Jūras Mickevičius ${ }^{3}(\mathbb{D}$, \\ Marcin Kryśko ${ }^{2}$, Paweł Piotr Michałowski ${ }^{4}$ (i) and Irmantas Kašalynas $1,5, *$ (I)
}

Citation: Jorudas, J.; Prystawko, P.; Šimukovič, A.; Aleksiejūnas, R.;

Mickevičius, J.; Kryśko, M.;

Michałowski, P.P.; Kašalynas, I.

Development of Quaternary

InAlGaN Barrier Layer for High

Electron Mobility Transistor

Structures. Materials 2022, 15, 1118.

https://doi.org/10.3390/

ma15031118

Academic Editor: Alexander

A. Lebedev

Received: 29 December 2021

Accepted: 28 January 2022

Published: 31 January 2022

Publisher's Note: MDPI stays neutral with regard to jurisdictional claims in published maps and institutional affiliations.

Copyright: () 2022 by the authors Licensee MDPI, Basel, Switzerland. This article is an open access article distributed under the terms and conditions of the Creative Commons Attribution (CC BY) license (https:// creativecommons.org/licenses/by/ $4.0 /)$.
1 Terahertz Photonics Laboratory, Center for Physical Sciences and Technology (FTMC), Saulètekio al. 3, LT-10257 Vilnius, Lithuania; arturas.simukovic@ftmc.lt

2 Institute of High Pressure Physics PAS (UNIPRESS), ul. Sokołowska 29/37, 01-142 Warsaw, Poland; pprysta@unipress.waw.pl (P.P.); krysko@unipress.waw.pl (M.K.)

3 Institute of Photonics and Nanotechnology, Vilnius University, Sauletekio al. 3, LT-10257 Vilnius, Lithuania; ramunas.aleksiejunas@ff.vu.lt (R.A.); juras.mickevicius@ff.vu.lt (J.M.)

4 Lukasiewicz Research Network-Institute of Microelectronics and Photonics, al. Lotników 32/46, 02-668 Warsaw, Poland; pawel.michalowski@imif.lukasiewicz.gov.pl

5 Institute of Applied Electrodynamics and Telecommunications, Vilnius University, Saulètekio al. 3, LT-10257 Vilnius, Lithuania

* Correspondence: justinas.jorudas@ftmc.lt (J.J.); irmantas.kasalynas@ftmc.lt (I.K.); Tel.: +370-5-231-2418 (I.K.)

\begin{abstract}
A quaternary lattice matched InAlGaN barrier layer with am indium content of $16.5 \pm 0.2 \%$ and thickness of $9 \mathrm{~nm}$ was developed for high electron mobility transistor structures using the metalorganic chemical-vapor deposition method. The structural, morphological, optical and electrical properties of the layer were investigated planning realization of microwave power and terahertz plasmonic devices. The measured $\mathrm{X}$-ray diffraction and modeled band diagram characteristics revealed the structural parameters of the grown $\operatorname{In}_{0.165} \mathrm{Al}_{0.775} \mathrm{Ga}_{0.06} \mathrm{~N} / \mathrm{Al}_{0.6} \mathrm{Ga}_{0.4} \mathrm{~N} / \mathrm{GaN}$ heterostructure, explaining the origin of barrier photoluminescence peak position at $3.98 \mathrm{eV}$ with the linewidth of $0.2 \mathrm{eV}$ and the expected red-shift of $0.4 \mathrm{eV}$ only. The thermally stable density of the two-dimension electron gas at the depth of $10.5 \mathrm{~nm}$ was experimentally confirmed to be $1.2 \times 10^{13} \mathrm{~cm}^{-2}\left(1.6 \times 10^{13} \mathrm{~cm}^{-2}\right.$ in theory) with the low-field mobility values of $1590 \mathrm{~cm}^{2} /(\mathrm{V} \cdot \mathrm{s})$ and $8830 \mathrm{~cm}^{2} /(\mathrm{V} \cdot \mathrm{s})$ at the temperatures of $300 \mathrm{~K}$ and $77 \mathrm{~K}$, respectively.
\end{abstract}

Keywords: InAlGaN; GaN; high electron mobility transistor structures; III-nitride heterostructures; microwave power devices; $\mathrm{THz}$ plasmonic devices

\section{Introduction}

Currently, III-nitride high electron mobility transistor (HEMT) structures based on the $\mathrm{AlGaN} / \mathrm{GaN}$ heterostructure are extensively used in various applications such as gas sensors [1,2], THz detectors [3-6] and emitters [7,8], and high-power microwave devices [9-12]. A combination of $\mathrm{InN}$ and AlN alloys with very different bandgaps, lattice and spontaneous polarization constants can be used to implement a wide range of electric and optic properties in the heterostructure [13-15]. In particular, the lattice-matched (LM) InAlN/GaN heterostructures are very attractive for the development of HEMTs as they possess no degradation due to mechanical stress and exhibit high chemical and thermal stability, demonstrated at up to $1000{ }^{\circ} \mathrm{C}[16,17]$. The use of thinner LM-InAlN barrier allows for the achievement of much higher two-dimensional electron gas (2DEG) densities than that in standard AlGaN/GaN HEMT structures with the same barrier thickness [18]. Moreover, barrier-layer scaling in InAlN/GaN HEMT structures down to $3 \mathrm{~nm}$ was demonstrated, exhibiting thermal stability (up to $1000{ }^{\circ} \mathrm{C}$ ) of the barrier interface with a GaN buffer and with surface metals, used for electric contacts [19]. All of the reported features of the $\mathrm{LM}-\mathrm{InAl}(\mathrm{Ga}) \mathrm{N} / \mathrm{GaN}$ HEMT structures were found to be very 
attractive for high power GaN-based electronic [11,20-22] and plasmonic devices [23,24]. In particular, optimal conditions for the excitation of 2D plasmons in standard AlGaN/GaN HEMT structures up to the room temperature were revealed recently [25]. Among other aspects, a shallow depth and a high density of 2DEG in grating-gated heterostructures allow for efficient plasmonic device operation in the THz regime [26]. In this work, the quaternary LM-InAlGaN barrier layer with indium content of $16.5 \pm 0.2 \%$ and thickness of only $9 \mathrm{~nm}$ was developed for GaN-based heterostructures on sapphire substrate and investigated studying material structural properties, optical and electrical characteristics of the test devices.

\section{Samples}

The heterostructure was developed on 2" diameter $430 \mu \mathrm{m}$ thick single-side polished sapphire substrate. The layers with a nominal thickness of $0.5 \mathrm{~nm}$ of GaN cap, $8.7 \mathrm{~nm}$ of $\mathrm{In}_{\mathrm{x}} \mathrm{Al}_{1-\mathrm{x}} \mathrm{N}$ barrier, $1.2 \mathrm{~nm}$ of $\mathrm{Al}_{0.66} \mathrm{Ga}_{0.34} \mathrm{~N}$ spacer, $600 \mathrm{~nm}$ of undoped $\mathrm{GaN}$ channel, and $3.2 \mu \mathrm{m} \mathrm{GaN}$ :C buffer on $25 \mathrm{~nm}$ low temperature $\mathrm{GaN}$ nucleation layer were grown along the polar $c$-axis using the metalorganic chemical vapor deposition (MOCVD) method in a Close Coupled Showerhead (CCS) Flip Top $3 \times 2$ inch reactor (Aixtron, Herzogenrath, Germany). A schematic diagram of the heterostructure layers is also discussed in Section 3.3. Of note, if the thickness of the AlN spacer is larger than $1 \mathrm{~nm}$, its role in the formation of 2DEG layer is not as significant due to the polarization discontinuity with the barrier, which was estimated to be of $0.73 \mathrm{eV}$ from the effective conduction band offset between the LM-InAlN and GaN [18]. Moreover, the target of a $\sim 9 \mathrm{~nm}$ thickness of the barrier was chosen as optimum for high values of 2DEG density and mobility [19], with an expectation for higher transconductance values due to the short distance between the transistor gate and a 2DEG channel.

The AFM image of an as-grown heterostructure was measured with Dimension 3100 AFM instrument (Veeco, TX, USA). The results are shown in Figure 1. The RMS roughness over the whole image area $\left(4 \times 4 \mu \mathrm{m}^{2}\right)$ was found to be $1.2 \mathrm{~nm}$. The threading dislocation density (TDD) was estimated over the area of $2 \times 2 \mu \mathrm{m}^{2}$, counting the pits, which are seen as the black color points in Figure 1. The value of TDD was around $2 \times 10^{9} \mathrm{~cm}^{-2}$.

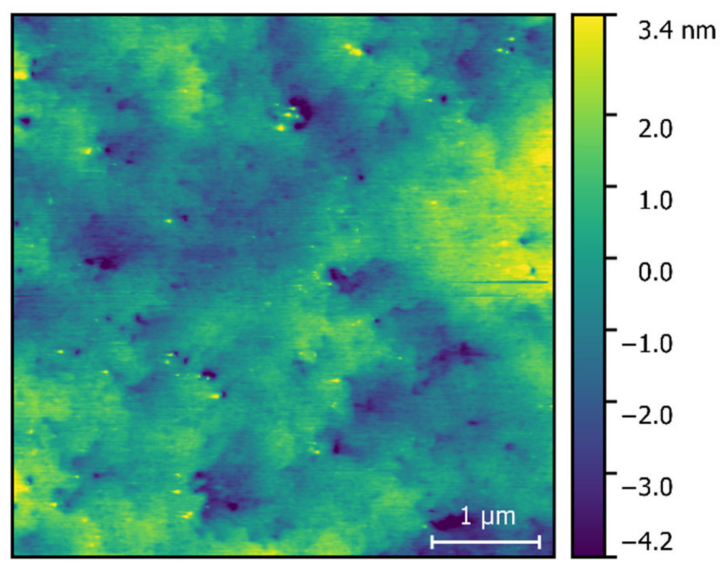

Figure 1. AFM image of the as-grown heterostructure.

The sheet resistance was measured by the microwave single-post dielectric resonator QWED SiPDR (QWED, Warsaw, Poland). At room temperature, the as-grown heterostructure demonstrated sheet resistance values of $350 \pm 1 \Omega /$ sq.

Mesas for test devices were fabricated using inductively coupled plasma reactive ion etching (ICP-RIE) (Oxford Instruments, Bristol, UK) via Cl plasma. For ohmic contacts, $\mathrm{Ti} / \mathrm{Al} / \mathrm{Ni} / \mathrm{Au}$ metal stack of thicknesses 30/90/20/150 nm were deposited and annealed in nitrogen ambient for $30 \mathrm{~s}$ at $850{ }^{\circ} \mathrm{C}$. Schottky contacts were formed of $25 / 150 \mathrm{~nm} \mathrm{Ni} / \mathrm{Au}$ stack. The set of the test devices consisted of Van der Pauw (VdP) structures, transmission 
line method (TLM) resistor array, HEMTs and Schottky barrier diodes (SBDs). Furthermore, test devices were left with an unpassivated nitride surface. More details about the device processing have been reported elsewhere [12,27].

Test TLM structures were used to estimate the resistance of ohmic contacts and the sheet resistance of the 2DEG layer. Their values were found to be of $1 \Omega \mathrm{mm}$ and $385 \Omega / \mathrm{sq}$., respectively. The ideality factor and Schottky barrier height were determined from forward biased current-voltage characteristics of the SBDs applying the thermionic emission model [28], demonstrating the values of about 2.3 and $0.7 \mathrm{eV}$, respectively.

\section{Results}

\subsection{Secondary-Ion Mass Spectrometry (SIMS) of the Heterostructure}

A SIMS analysis of as-grown heterostructure was performed in order to determine impurity density and distribution of atomic fractions in the layers. In this work SIMS depth profiles were performed employing the SC Ultra instrument (CAMECA, Gennevilliers, France) under ultra-high vacuum. The amount of residual oxygen, carbon, and silicon impurities in the GaN channel layer were found from the calibrated SIMS data to be of $(3.7 \pm 1.3) \times 10^{16} \mathrm{~cm}^{-3},(5.1 \pm 0.3) \times 10^{16} \mathrm{~cm}^{-3}$, and $(1.0 \pm 0.6) \times 10^{16} \mathrm{~cm}^{-3}$, respectively. The amount of these impurities was close to that obtained by the low-frequency noise and THz electroluminescence spectroscopy methods in the AlGaN/GaN HEMT on sapphire $[27,29]$.

Figure 2 demonstrates the very uniform distribution of each atomic fraction along the growth direction of the heterostructure layers. A small fraction of $\mathrm{Ga}$ was found in the barrier, which occasionally occurs during the growth of the InAlN barrier in MOCVD reactor [30-32]. However, the CCS tools are known to accumulate the gallium-containing material on the inlet showerhead flange upstream the substrates. This deposit can be the unintentional source of the gallium incorporated into the main barrier layer grown and enhanced by TMIn and hydrogen carrier gas delivery [30].

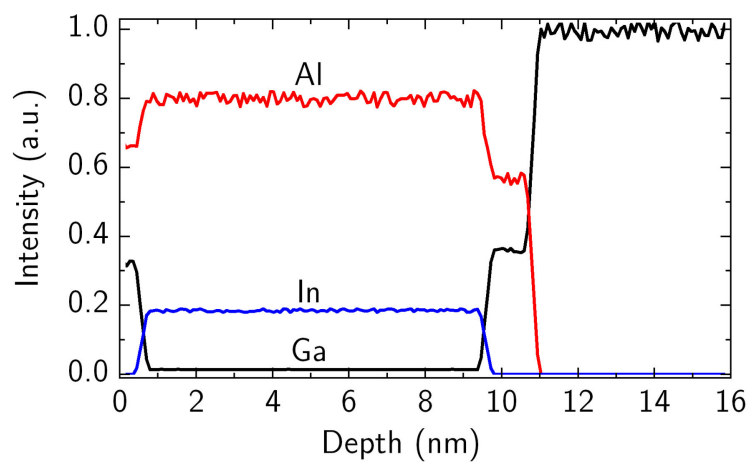

Figure 2. SIMS profile of $\mathrm{Ga}$, In, and $\mathrm{Al}$ in the heterostructure under study.

\subsection{X-ray Diffraction (XRD) Analysis of the Heterostructure}

The crystal quality, layer thicknesses and composition of as-grown heterostructure were investigated by HR-XRD analysis (Malvern Panalitycal X'pert MRD, Almelo, Netherlands). The XRD results of as-grown heterostructure are shown in Figure 3. With the assumption that the Ga concentration was $6 \%$, other concentrations were found to be of $16.5 \pm 0.2 \%$ In (error coming from fitting of the simulation) and $77.5 \pm 0.2 \%$ Al. To calculate the fitted curve the dynamical diffraction theory was used. Errors coming from uncertainty of elastic constants were negligible as the layer was not strained. Additionally, lattice constant, $a$, of the quaternary barrier was calculated with Nextnano++ software (Nextnano $\mathrm{GmbH}$, München, Germany). The lattice matching to GaN with deviation of $a_{\Delta}=\left(\left(a_{\text {Barier }}-a_{\text {GaN }}\right) / a_{G a N}\right) \times 100 \%$ was found to be as small as $-0.03 \%$. Moreover, a single layer of $30 \mathrm{~nm}$ thick $\operatorname{InAl}(\mathrm{Ga}) \mathrm{N}$ was grown on the $\mathrm{GaN}$ template using the same 
growth conditions as for the investigated heterostructure. The XRD experiment confirmed that the barrier layer is lattice matched to GaN.

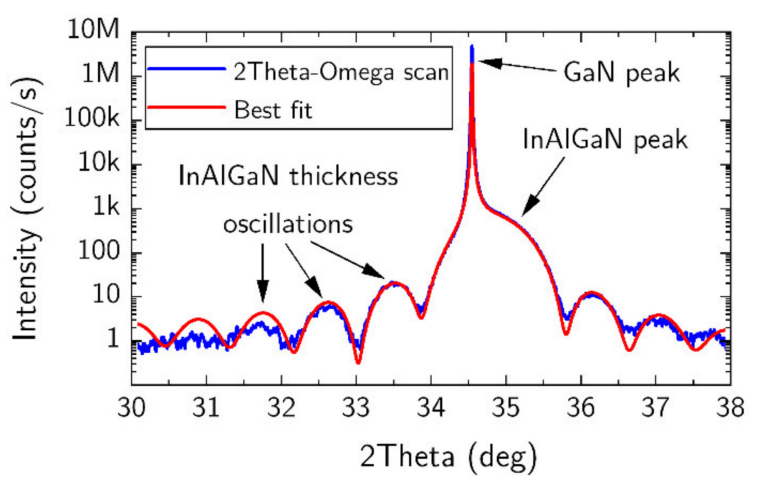

Figure 3. Experimental HR-XRD curve (blue line) and the best fit (red line) of the heterostructure with quaternary barrier composition of $16.5 \pm 0.2 \%, 77.5 \pm 0.2 \%$, and $6 \%$ for $\mathrm{In}, \mathrm{Al}$, and $\mathrm{Ga}$, respectively, and thickness of $8.6 \mathrm{~nm}$.

It is worth discussing the algorithm used in our work for the development of the LM barrier layers. Our method to assess the InAlN (In $=18 \%$, AlN $=82 \%$ ) barrier composition the path was as follows:

(i). we made expected calculations of the gas-phase with surplus indium and aluminum precursors only, without flowing the gallium,

(ii). we grew 30-50 $\mathrm{nm}$ thick calibration samples on GaN/Sapphire increasing the growth temperature and checking for lattice-matching to GaN in-plane lattice compatibility by HR-XRD,

(iii). we applied the preferred high growth temperature and the growth rate to the HEMT final structure, growing a $9 \mathrm{~nm}$ thick LM-InAlGaN barrier.

We assumed that some gallium was incorporated into the barrier as expected from similar studies in literature while using the CCS reactors [30]. Therefore, the density of 2DEG and the band gap of barrier layer were experimentally investigated and simulated using Nextnano++ software (see details in next sections). Based on the Nextnano++ results, much higher 2DEG density for nominal ternary composition was expected, therefore, in simulation of HR-XRD data, we iteratively added Ga to the barrier, removing some In and $\mathrm{Al}$ but keeping the original $\mathrm{Al} / \mathrm{In}$ ratio. In this way, the polarization influence on actual 2DEG concentration was decreased until a reasonable agreement between simulation and measurement values were obtained.

\subsection{Band Diagram of the Heterostructure}

Nextnano++ software was used to calculate the bandgap, lattice constant, 2DEG density in the heterostructure using the layers thicknesses from the growth protocol and quaternary barrier composition from the XRD analysis. The results of modeling are shown in Figure 4. It has been shown that for the best lattice-matching the $\mathrm{Al} / \mathrm{In}$ ratio should be $4.63[33,34]$. The composition of the modeled quaternary heterostructure demonstrated a very similar $\mathrm{Al} / \mathrm{In}$ ratio of 4.70 . Furthermore, its bandgap of $4.36 \mathrm{eV}$ (Figure $4 \mathrm{a}$ ) was found to be very close to that of ternary $\operatorname{In}_{x} \mathrm{Al}_{1-\mathrm{x}} \mathrm{N}$ barrier with an In fraction of $18 \%$ with $E_{\mathrm{G}}=4.39 \mathrm{eV}$ (not shown). Finally, the calculated 2DEG density in the quaternary heterostructure was found to be of about $1.6 \times 10^{13} \mathrm{~cm}^{-2}$. 

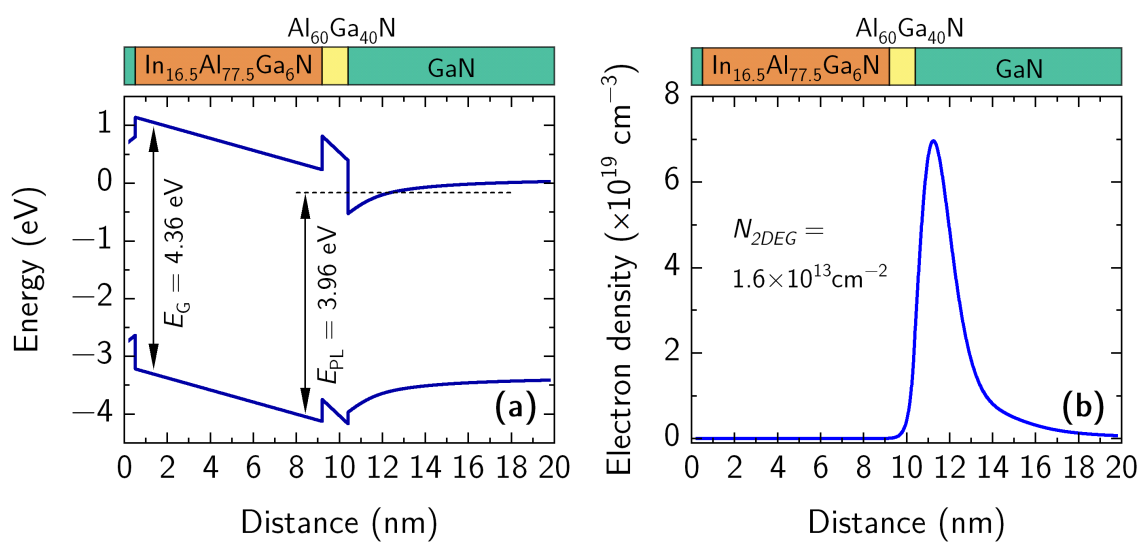

Figure 4. Band diagram (a) and 2DEG distribution (b) in the heterostructure calculated using the barrier composition determined from XRD measurements. A schematic representation of the heterostructure layout is provided above the figures.

\subsection{Two-Dimensional Electron Gas (2DEG)}

The carrier density, mobility, and sheet resistance of the 2DEG were determined in Hall experiment using Van der Pauw structures at two temperatures, $77 \mathrm{~K}$ and $300 \mathrm{~K}$. The sheet carrier density at both temperatures was $1.2 \times 10^{13} \mathrm{~cm}^{-2}$, with an uncertainty of $3 \%$. Meanwhile, the mobility increased with the decrease in temperature from $1590 \mathrm{~cm}^{2} \mathrm{~V}^{-1} \mathrm{~s}^{-1}$ at $300 \mathrm{~K}$ to $8830 \mathrm{~cm}^{2} \mathrm{~V}^{-1} \mathrm{~s}^{-1}$ at $77 \mathrm{~K}$, resulting in the change in sheet resistance from $320 \Omega$ /sq. to $60 \Omega$ /sq., respectively. A small difference in the 2DEG density between calculated $1.6 \times 10^{13} \mathrm{~cm}^{-2}$ and measured $1.2 \times 10^{13} \mathrm{~cm}^{-2}$ values can be explained by the heterostructure material sensitivity to the device fabrication steps such as chemical treatment, ion plasma etching, metal electrode deposition, and non-controlled surface unintentional passivation [12,27].

\subsection{Schottky Contact to 2DEG}

The capacitance-voltage $(\mathrm{C}-\mathrm{V})$ characteristics of the fabricated Schottky contacts to the 2DEG layer were measured on the EPS150 probe station (Cascade Microtech, Beaverton, OR, USA) using precision impedance analyzer Agilent 4294A (Agilent, Santa Clara, CA, USA). Typical C-V characteristic of the circular SBD with $5 \mu \mathrm{m}$ separation between ohmic-Schottky contacts and $80 \mu \mathrm{m}$ diameter of inner Schottky pad are shown in Figure 5a. Data linear extrapolation to abscissa allowed us to determine the pinch-off voltage, $V_{\mathrm{p}-\mathrm{o}}$, which was found at $-1.74 \mathrm{~V}$. The $\mathrm{C}-\mathrm{V}$ results allowed us to estimate the dependence of carrier density, $N$, on the distance from the surface, $\mathrm{W}$, employing the method described elsewhere [35]. The position of the 2DEG under the Schottky contact was found to be $10.5 \mathrm{~nm}$ from surface, which is very close to the nominal value of $10.4 \mathrm{~nm}$ defined from the growth protocol. It is worth noting that the high 2DEG density was achieved with a barrier thickness of only 9 $\mathrm{nm}$. This is less than a half of the AlGaN barrier layer thickness, which usually varies from 20 to $25 \mathrm{~nm}$ in standard AlGaN/GaN HEMT structures [12,27].

\subsection{Photoluminescence of the Heterostructure}

The photoluminescence (PL) spectra of as-grown heterostructure were measured using an optical parametric oscillator (OPO, Ekspla NT342B, Vilnius, Lithuania) for the excitation, generating four ns-pulses with peak power density of about $200 \mathrm{~kW} / \mathrm{cm}^{2}$ and $3 \mathrm{MW} / \mathrm{cm}^{2}$ at the selected wavelength of $300 \mathrm{~nm}$ and $250 \mathrm{~nm}$, respectively. Measured PL spectra are shown in Figure 6. At the excitation wavelength of $300 \mathrm{~nm}$ (black line in Figure 6), electron recombination in GaN barrier was probed only, demonstrating a Lorentz-shape band at the position of $3.42 \mathrm{eV}$ with full width at half maximum (FWHM) of $90 \mathrm{meV}$. At the excitation wavelength of $250 \mathrm{~nm}$, the broad band centered at around $3.98 \mathrm{eV}$ with FWHM $=200 \mathrm{meV}$ was measured in the PL spectrum (red line in Figure 6), revealing the contribution of InAlGaN barrier $[36,37]$. 

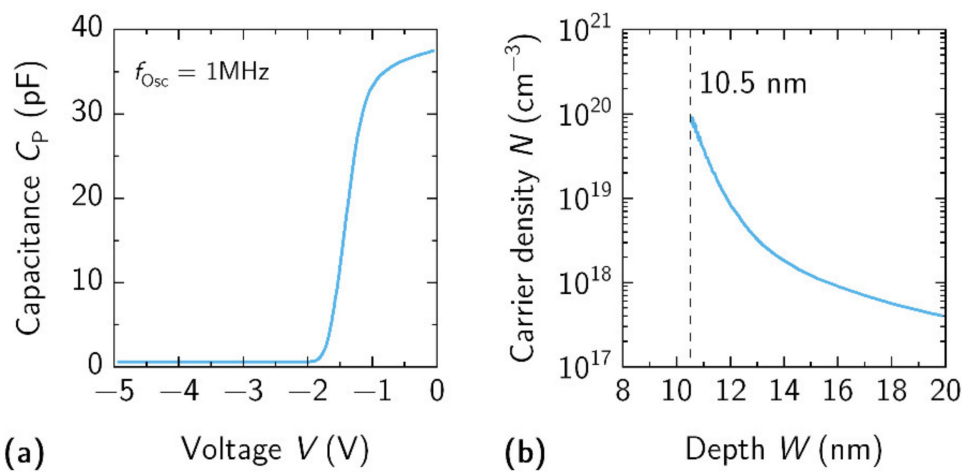

Figure 5. (a) Capacitance-voltage (at $1 \mathrm{MHz}$ ) measurements for circular SBD with $\varnothing 80 \mu \mathrm{m}$ inner Schottky contact pad which is separated from outer ohmic contact by $5 \mu \mathrm{m}$. (b) Measured distribution of carrier density in the heterostructure. The position of 2DEG was found at $10.5 \mathrm{~nm}$ as marked by dashed vertical line.

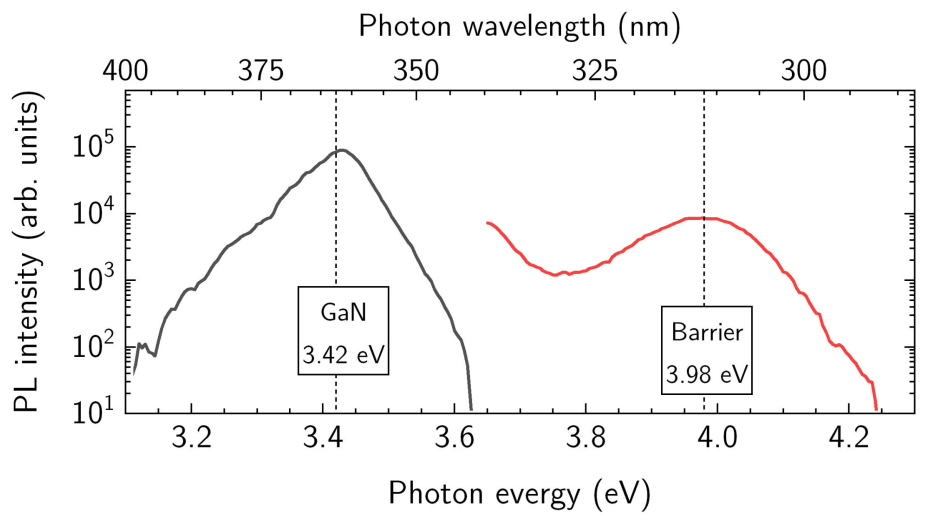

Figure 6. PL spectra of the heterostructure measured using different excitation wavelength and peak power density of $300 \mathrm{~nm}$ and $200 \mathrm{~kW} / \mathrm{cm}^{2}$ (black line) and $250 \mathrm{~nm}$ and $3 \mathrm{MW} / \mathrm{cm}^{2}$ (red line), respectively.

The results of the PL measurements (see Figure 6) demonstrate a $0.40 \mathrm{eV}$ red-shift from the expected bandgap energy of the quaternary barrier (see Figure 4a). Such a red-shift of the PL peak was sufficiently small in comparison to the Stokes shifts reported for similar heterostructures with InAlN barrier exhibiting values in the range of $0.4-1 \mathrm{eV}$ [36-40]. Various explanations of the Stokes shift were proposed such as the introduction of sub-band edge states near the band edge minima which induce strain and related alloy composition fluctuations [41], local variations of the number of Al and In atoms surrounding nitrogen atom [42] or radiative recombination between the electrons in the triangular quantum well (2DEG) and photoexcited holes efficiently transferred from InAlN to GaN via sub-band-gap states [37].

Taking into account the energy levels of the barrier conduction band in the vicinity of $\mathrm{Al}_{0.66} \mathrm{Ga}_{0.34} \mathrm{~N}$ spacer $(237 \mathrm{meV})$ and of $2 \mathrm{DEG}(-162 \mathrm{meV})$ with respect to the barrier bandgap $(4.36 \mathrm{eV})$, the modified bandgap was estimated to be of about $E_{\mathrm{PL}}=3.96 \mathrm{eV}$, which is close to the measured PL peak position at $3.98 \mathrm{eV}$. Additionally, the evaluation of the transition energies in $c$-plane grown heterostructure is somehow affected by carrier confinement and the built-in electric field. Therefore, the developed quaternary heterostructure requires a more detailed investigation of photo-carrier transport and a direct comparison of PL spectra with the results of other methods able to determine the bandgap of barrier layer such as a photoluminescence excitation (PLE), cathode photoluminescence (CL), and reflection modulated spectroscopy. 


\subsection{Application of the Heterostructure for Electronic Devices}

The SBDs were processed without surface passivation and investigated in the reverse bias regime in order to find the breakdown fields. The results are shown in Figure 7. For the $5 \mu \mathrm{m}$ contact separation, SBD breakdown occurred at the electric field of $0.43 \mathrm{MV} / \mathrm{cm}$ (Figure 7 solid line). For the largest contact separation of $40 \mu \mathrm{m}$, the breakdown field value decreased to $0.05 \mathrm{MV} / \mathrm{cm}$ (Figure 7 dashed line). The breakdown of the SBD was found to occur via the surface defects and threading dislocations, both of which create shunting paths for the leakage current, the value of which before the breakdown (at (-200)-(-230) V) was up to $2.14 \mathrm{~mA} / \mathrm{mm}$. Furthemore, the SBDs with larger contact separation had a larger active area, which includes more defect and threading dislocations [43-46]. We would think that large leakage currents could cause a thermal breakdown of the device.

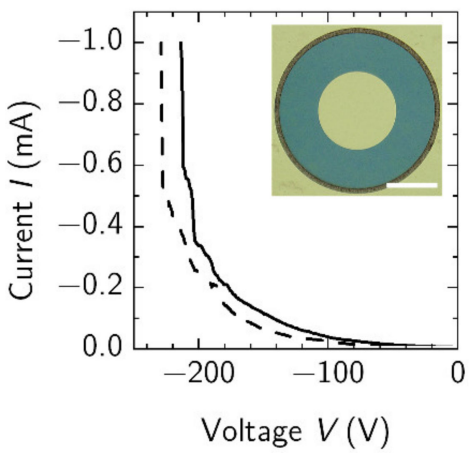

Figure 7. Breakdown of two SBDs with contact spacings of $5 \mu \mathrm{m}$ (solid line) and $40 \mu \mathrm{m}$ (dashed line). Current was limited to $1 \mathrm{~mA}$ level. Inset-microscope image of the SBD with diameter of central Schottky contact and distance to ohmic contact being of $80 \mu \mathrm{m}$ and $40 \mu \mathrm{m}$, respectively.

The HEMTs were also processed and studied on the wafer in DC and RF regimes using the Süss Microtech probe station PM8 (FormFactor Inc., Livermore Inc., Livermore, CA, USA). For the RF measurements the G-S-G (ground-signal-ground) high frequency probes, an E8364B PNA Network Analyzer (Keysight Technologies, Santa Rosa, CA, USA), and E5270B Precision IV Analyzer with IC-CAP software were used (Keysight Technologies, Santa Rosa, CA, USA). The two-step open-short de-embedding method was implemented, and small signal S-parameters were obtained. The unity current gain-cut-off frequency $\left(f_{\mathrm{T}}\right)$ and the unity maximum unilateral power gain frequency $\left(f_{\max }\right)$ were found from de-embedded S-parameter frequency characteristics.

Each HEMT was developed in G-S-G device configuration with $W_{\mathrm{Ch}}=2 \mu \mathrm{m} \times 200 \mu \mathrm{m}$, $L_{\mathrm{ds}}=12 \mu \mathrm{m}$ and $L_{\mathrm{g}}=5 \mu \mathrm{m}$. The results for HEMTs characterization in DC and RF regimes are shown in Figure 8. Output characteristics demonstrate (see Figure 8a) the effect of very low pinch-off voltage, where the channel is fully closed at $V_{\mathrm{gs}}=-2 \mathrm{~V}$. The highest output drain current was recorded at $V_{\mathrm{ds}}=6 \mathrm{~V}$ and $V_{\mathrm{gs}}=1 \mathrm{~V}$, reaching up to $200 \mathrm{~mA} / \mathrm{mm}$, which deteriorate with further increase in drain voltage due to excess heat accumulation in the conductive channel. The transfer curve for the same device at $V_{\mathrm{ds}}=5 \mathrm{~V}$ is shown in Figure $8 \mathrm{~b}$. Large leakage currents were observed both in the drain and gate contacts under negative gate bias. The $I_{\text {on }} / I_{\text {off }}$ ratio for the HEMT was limited to the value of $26 \mathrm{~dB}$. The small-signal transconductance values for this device were measured to be up to $117 \mathrm{mS} / \mathrm{mm}$ at $V_{\mathrm{gs}}=+0.6 \mathrm{~V}$. The results of RF characterization are shown in Figure 8c. The highest $f_{\mathrm{T}}$ and $f_{\max }$ values at $V_{\mathrm{ds}}=5 \mathrm{~V}$ and $V_{\mathrm{gs}}=0.2 \mathrm{~V}$ were estimated to be up to $0.95 \mathrm{GHz}$ and $4.5 \mathrm{GHz}$, respectively. The figure of merit value $f_{\mathrm{T}} \times L_{\mathrm{g}}$ for the investigated HEMT was of $4.3 \mathrm{GHz} \times \mu \mathrm{m}$, which is about two times lower than $10 \mathrm{GHz} \times \mu \mathrm{m}$, reported for the scaled HEMTs made of similar InAl(Ga)N/GaN heterostructures [10,47]. The difference can be explained by a simplified design of our transistors due to the usage of standard UV photolithography instead of e-beam lithography. 

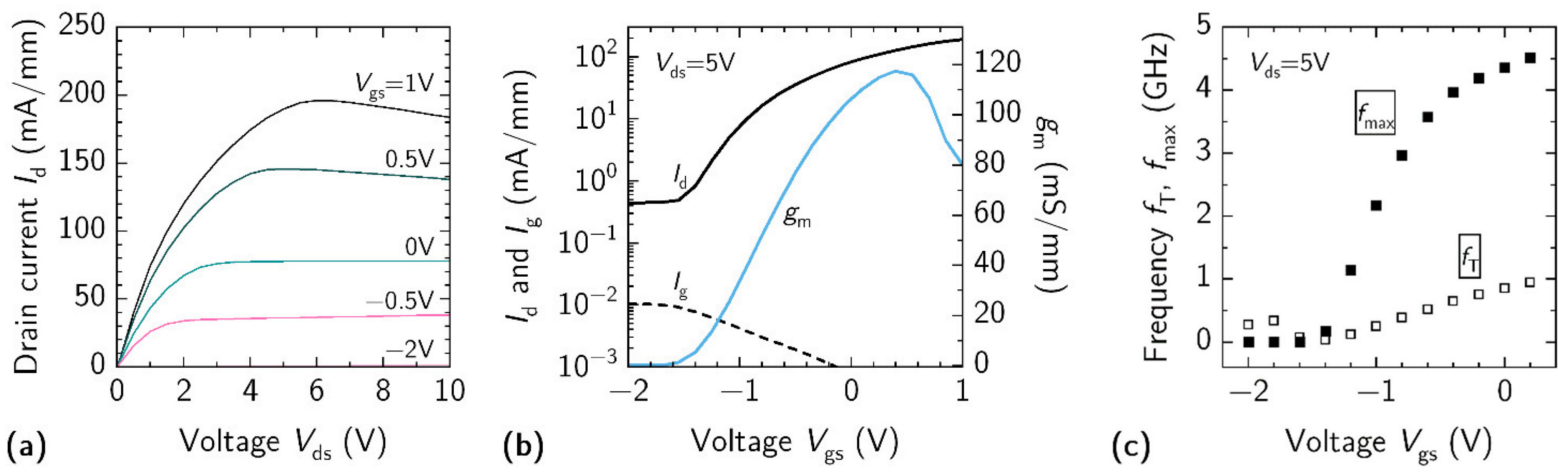

Figure 8. (a) Output characteristics, (b) transfer characteristics and (c) $f_{\mathrm{T}}$ and $f_{\max }$ frequencies measured for the same HEMT with $L_{\mathrm{g}}=5 \mu \mathrm{m}$ and $L_{\mathrm{ds}}=12 \mu \mathrm{m}$.

\section{Conclusions}

A quaternary LM InAlGaN barrier layer with an indium content of $16.5 \pm 0.2 \%$ and thickness of only $9 \mathrm{~nm}$ has been developed for high electron mobility transistor structures by metalorganic chemical vapor deposition method. A detailed analysis of the structural, morphological, optical and electrical properties revealed the composition of the barrier layer to be $16.5 \pm 0.2 \%$ of In, $77.5 \pm 0.2 \%$ of $\mathrm{Al}$, and $6 \%$ of $\mathrm{Ga}$, and allowed us to explain the origin of barrier photoluminescence peak position observed at $3.98 \mathrm{eV}$ with the linewidth of $0.2 \mathrm{eV}$ and the expected red-shift of $0.4 \mathrm{eV}$ only. The thermally stable density of the two-dimension electron gas at the depth of $10.5 \mathrm{~nm}$ was experimentally confirmed to be of $1.2 \times 10^{13} \mathrm{~cm}^{-2}\left(1.6 \times 10^{13} \mathrm{~cm}^{-2}\right.$ in theory $)$ with low-field mobility values of $1590 \mathrm{~cm}^{2} /(\mathrm{V} \cdot \mathrm{s})$ and $8830 \mathrm{~cm}^{2} /(\mathrm{V} \cdot \mathrm{s})$ at the temperatures of $300 \mathrm{~K}$ and $77 \mathrm{~K}$, respectively. The fabricated Schottky barrier diodes allowed us to determine the pinch-off voltage to be $-1.74 \mathrm{~V}$ and breakdown field to be $0.4 \mathrm{MV} / \mathrm{cm}$ for this heterostructure. The HEMTs fabricated of this heterostructure were tested both in $\mathrm{dc}$ and $\mathrm{rf}$ regimes and show similar performance to the standard AlGaN/GaN HEMTs, considering that a substantially thinner barrier layer was used. Overall, the results presented in our work indicate that the developed heterostructure with quaternary LM-InAlGaN barrier is a promising candidate for microwave power electronic and plasmonic devices operating in the $\mathrm{THz}$ range.

Author Contributions: Conceptualization, P.P. and I.K.; investigation, J.J., P.P., A.Š., R.A., J.M., M.K., P.P.M. and I.K.; data curation, J.J., P.P. and I.K.; writing-original draft preparation, J.J. and I.K.; writing-review and editing, J.J., P.P., R.A. and I.K.; visualization, J.J. and I.K.; supervision, P.P. and I.K.; project administration, I.K.; funding acquisition, P.P. and I.K. All authors have read and agreed to the published version of the manuscript.

Funding: The work was supported by the Research Council of Lithuania (Lietuvos mokslo taryba) under the "TERAGANWIRE" project (Grant No. S-LL-19-1), by the National Science Center of Poland (Grant No. 2017/27/L/ST7/03283), by “International Research Agendas" program of the Foundation for Polish Science co-financed by the European Union under the European Regional Development Fund (Nos. MAB/2018/9), and partially supported by the Polish National Center for Research and Development through projects No. WPC/20/DefeGaN/2018 and No. TECHMATSTRATEGIII $/ 0003 / 2019$.

Institutional Review Board Statement: Not applicable.

Informed Consent Statement: Not applicable.

Data Availability Statement: The data presented in this study are available on request from the corresponding author. The data are not publicly available due to privacy.

Conflicts of Interest: The authors declare no conflict of interest. 


\section{References}

1. Ahn, J.; Kim, D.; Park, K.-H.; Yoo, G.; Heo, J. Pt-Decorated Graphene Gate AlGaN/GaN MIS-HEMT for Ultrahigh Sensitive Hydrogen Gas Detection. IEEE Trans. Electron Devices 2021, 68, 1255-1261. [CrossRef]

2. Nguyen, V.C.; Kim, K.; Kim, H. Performance Optimization of Nitrogen Dioxide Gas Sensor Based on Pd-AlGaN/GaN HEMTs by Gate Bias Modulation. Micromachines 2021, 12, 400. [CrossRef] [PubMed]

3. Sun, J.; Feng, W.; Ding, Q.; Zhu, Y.; Zhang, Z.; Li, X.; Qin, H.; Zhang, J.; Li, X.; Shangguan, Y.; et al. Smaller Antenna-Gate Gap for Higher Sensitivity of GaN/AlGaN HEMT Terahertz Detectors. Appl. Phys. Lett. 2020, 116, 161109. [CrossRef]

4. Yang, L.; Yao, W.; Liu, Y.; Wang, L.; Dai, Y.; Liu, H.; Wang, F.; Ren, Y.; Wu, Z.; Liu, Y.; et al. Low Capacitance AlGaN/GaN Based Air-Bridge Structure Planar Schottky Diode with a Half through-Hole. AIP Adv. 2020, 10, 045219. [CrossRef]

5. Bauer, M.; Ramer, A.; Chevtchenko, S.A.; Osipov, K.Y.; Cibiraite, D.; Pralgauskaite, S.; Ikamas, K.; Lisauskas, A.; Heinrich, W.; Krozer, V.; et al. A High-Sensitivity AlGaN/GaN HEMT Terahertz Detector With Integrated Broadband Bow-Tie Antenna. IEEE Trans. Terahertz Sci. Technol. 2019, 9, 430-444. [CrossRef]

6. Jorudas, J.; Malakauskaitė, J.; Subačius, L.; Janonis, V.; Jakštas, V.; Kovalevskij, V.; Kašalynas, I.; Malakauskaite, J.; Subacius, L.; Janonis, V.; et al. Development of the Planar AlGaN/GaN Bow-Tie Diodes for Terahertz Detection. In Proceedings of the 2019 44th International Conference on Infrared, Millimeter and Terahertz Waves (IRMMW-THz), Paris, France, 1-6 September 2019; pp. 1-2. [CrossRef]

7. El Fatimy, A.; Dyakonova, N.; Meziani, Y.; Otsuji, T.; Knap, W.; Vandenbrouk, S.; Madjour, K.; Théron, D.; Gaquiere, C.; Poisson, M.A.; et al. AlGaN/GaN High Electron Mobility Transistors as a Voltage-Tunable Room Temperature Terahertz Sources. J. Appl. Phys. 2010, 107, 24504. [CrossRef]

8. Janonis, V.; Pashnev, D.; Grigelionis, I.; Korotieiev, V.; Balagula, R.M.; Minkevicius, L.; Jorudas, J.; Alexeeva, N.; Subacius, L.; Valušis, G.; et al. Electrically-Pumped THz Emitters Based on Plasma Waves Excitation in III-Nitride Structures. In Terahertz Emitters, Receivers, and Applications XI; Razeghi, M., Baranov, A.N., Eds.; SPIE: Washington, DC, USA, 2020; Volume 11499, p. 8. [CrossRef]

9. Romanczyk, B.; Mishra, U.K.; Zheng, X.; Guidry, M.; Li, H.; Hatui, N.; Wurm, C.; Krishna, A.; Ahmadi, E.; Keller, S. W-Band Power Performance of SiN-Passivated N-Polar GaN Deep Recess HEMTs. IEEE Electron Device Lett. 2020, 41, 349-352. [CrossRef]

10. Shinohara, K.; Regan, D.C.; Tang, Y.; Corrion, A.L.; Brown, D.F.; Wong, J.C.; Robinson, J.F.; Fung, H.H.; Schmitz, A.; Oh, T.C.; et al. Scaling of GaN HEMTs and Schottky Diodes for Submillimeter-Wave MMIC Applications. IEEE Trans. Electron Devices 2013, 60, 2982-2996. [CrossRef]

11. Hassan, A.; Savaria, Y.; Sawan, M. GaN Integration Technology, an Ideal Candidate for High-Temperature Applications: A Review. IEEE Access 2018, 6, 78790-78802. [CrossRef]

12. Jorudas, J.; Šimukovič, A.; Dub, M.; Sakowicz, M.; Prystawko, P.; Indrišiūnas, S.; Kovalevskij, V.; Rumyantsev, S.; Knap, W.; Kašalynas, I. AlGaN/GaN on SiC Devices without a GaN Buffer Layer: Electrical and Noise Characteristics. Micromachines 2020, 11, 1131. [CrossRef]

13. Kuzmík, J. InAlN/(In)GaN High Electron Mobility Transistors: Some Aspects of the Quantum Well Heterostructure Proposal. Semicond. Sci. Technol. 2002, 17, 540-544. [CrossRef]

14. Kuzmík, J.; Kostopoulos, A.; Konstantinidis, G.; Carlin, J.F.; Georgakilas, A.; Pogany, D. InAlN/GaN HEMTs: A First Insight into Technological Optimization. IEEE Trans. Electron Devices 2006, 53, 422-426. [CrossRef]

15. Kuzmík, J. Power Electronics on InAlN/(In)GaN: Prospect for a Record Performance. IEEE Electron Device Lett. 2001, 22, 510-512. [CrossRef]

16. Maier, D.; Alomari, M.; Grandjean, N.; Carlin, J.-F.; Diforte-Poisson, M.-A.; Dua, C.; Delage, S.; Kohn, E. InAlN/GaN HEMTs for Operation in the 1000 C Degrees Regime: A First Experiment. IEEE Electron Device Lett. 2012, 33, 985-987. [CrossRef]

17. Medjdoub, F.; Carlin, J.-F.; Gonschorek, M.; Feltin, E.; Py, M.A.; Ducatteau, D.; Gaquiere, C.; Grandjean, N.; Kohn, E. Can InAlN/GaN Be an Alternative to High Power/High Temperature AlGaN/GaN Devices? In Proceedings of the 2006 International Electron Devices Meeting, San Francisco, CA, USA, 11-13 December 2006; pp. 1-4. [CrossRef]

18. Gonschorek, M.; Carlin, J.-F.; Feltin, E.; Py, M.A.; Grandjean, N.; Darakchieva, V.; Monemar, B.; Lorenz, M.; Ramm, G. TwoDimensional Electron Gas Density in $\mathrm{Al}_{1-\mathrm{x}} \mathrm{In}_{\mathrm{x}} \mathrm{N} / \mathrm{AlN} / \mathrm{GaN}$ Heterostructures $(0.03 \leq \mathrm{x} \leq$ 0.23). J. Appl. Phys. 2008, 103,093714 . [CrossRef]

19. Medjdoub, F.; Alomari, M.; Carlin, J.F.; Gonschorek, M.; Feltin, E.; Py, M.A.; Grandjean, N.; Kohn, E. Barrier-Layer Scaling of InAlN/GaN HEMTs. IEEE Electron Device Lett. 2008, 29, 422-425. [CrossRef]

20. Liu, Y.; Jiang, H.; Arulkumaran, S.; Egawa, T.; Zhang, B.; Ishikawa, H. Demonstration of Undoped Quaternary AlInGaN/GaN Heterostructure Field-Effect Transistor on Sapphire Substrate. Appl. Phys. Lett. 2005, 86, 223510. [CrossRef]

21. Wang, R.; Li, G.; Karbasian, G.; Guo, J.; Song, B.; Yue, Y.; Hu, Z.; Laboutin, O.; Cao, Y.; Johnson, W.; et al. Quaternary Barrier InAlGaN HEMTs With FT/Fmax of 230/300 GHz. IEEE Electron Device Lett. 2013, 34, 378-380. [CrossRef]

22. Lecourt, F.; Agboton, A.; Ketteniss, N.; Behmenburg, H.; Defrance, N.; Hoel, V.; Kalisch, H.; Vescan, A.; Heuken, M.; de Jaeger, J.-C. Power Performance at $40 \mathrm{GHz}$ on Quaternary Barrier InAlGaN/GaN HEMT. IEEE Electron Device Lett. 2013, 34, 978-980. [CrossRef]

23. Shur, M.S. Terahertz Plasmonic Technology. IEEE Sens. J. 2021, 21, 12752-12763. [CrossRef]

24. Shur, M.; Aizin, G.; Otsuji, T.; Ryzhii, V. Plasmonic Field-Effect Transistors (TeraFETs) for 6G Communications. Sensors 2021, 21, 7907. [CrossRef] [PubMed] 
25. Pashnev, D.; Korotyeyev, V.V.; Jorudas, J.; Kaplas, T.; Janonis, V.; Urbanowicz, A.; Kašalynas, I. Experimental Evidence of Temperature Dependent Effective Mass in AlGaN/GaN Heterostructures Observed via THz Spectroscopy of 2D Plasmons. Appl. Phys. Lett. 2020, 117, 162101. [CrossRef]

26. Pashnev, D.; Kaplas, T.; Korotyeyev, V.; Janonis, V.; Urbanowicz, A.; Jorudas, J.; Kašalynas, I. Terahertz Time-Domain Spectroscopy of Two-Dimensional Plasmons in AlGaN/GaN Heterostructures. Appl. Phys. Lett. 2020, 117, 051105. [CrossRef]

27. Sai, P.; Jorudas, J.; Dub, M.; Sakowicz, M.; Jakštas, V.; But, D.B.; Prystawko, P.; Cywinski, G.; Kašalynas, I.; Knap, W.; et al. Low Frequency Noise and Trap Density in GaN/AlGaN Field Effect Transistors. Appl. Phys. Lett. 2019, 115, 183501. [CrossRef]

28. Schroder, D.K. Contact Resistance and Schottky Barriers. In Semiconductor Material and Device Characterization; John Wiley \& Sons, Inc.: Hoboken, NJ, USA, 2005; pp. 127-184.

29. Grigelionis, I.; Jorudas, J.; Jakštas, V.; Janonis, V.; Kašalynas, I.; Prystawko, P.; Kruszewski, P.; Leszczyński, M. Terahertz Electroluminescence of Shallow Impurities in AlGaN/GaN Heterostructures at $20 \mathrm{~K}$ and $110 \mathrm{~K}$ Temperature. Mater. Sci. Semicond. Process. 2019, 93, 280-283. [CrossRef]

30. Kim, J.; Lochner, Z.; Ji, M.-H.; Choi, S.; Kim, H.J.; Kim, J.S.; Dupuis, R.D.; Fischer, A.M.; Juday, R.; Huang, Y.; et al. Origins of Unintentional Incorporation of Gallium in InAlN Layers during Epitaxial Growth, Part II: Effects of Underlying Layers and Growth Chamber Conditions. J. Cryst. Growth 2014, 388, 143-149. [CrossRef]

31. Naresh-Kumar, G.; Vilalta-Clemente, A.; Pandey, S.; Skuridina, D.; Behmenburg, H.; Gamarra, P.; Patriarche, G.; Vickridge, I.; di Forte-Poisson, M.A.; Vogt, P.; et al. Multicharacterization Approach for Studying $\operatorname{InAl}(\mathrm{Ga}) \mathrm{N} / \mathrm{Al}(\mathrm{Ga}) \mathrm{N} / \mathrm{GaN}$ Heterostructures for High Electron Mobility Transistors. AIP Adv. 2014, 4, 127101. [CrossRef]

32. Hiroki, M.; Oda, Y.; Watanabe, N.; Maeda, N. Unintentional Ga Incorporation in Metalorganic Vapor Phase Epitaxy of InContaining III-Nitride Semiconductors. J. Cryst. Growth 2013, 382, 36-40. [CrossRef]

33. Rahimzadeh Khoshroo, L.; Ketteniss, N.; Mauder, C.; Behmenburg, H.; Woitok, J.F.; Booker, I.; Gruis, J.; Heuken, M.; Vescan, A.; Kalisch, H.; et al. Quaternary Nitride Heterostructure Field Effect Transistors. Phys. Status Solidi C 2010, 7, 2001-2003. [CrossRef]

34. Ketteniss, N.; Khoshroo, L.R.; Eickelkamp, M.; Heuken, M.; Kalisch, H.; Jansen, R.H.; Vescan, A. Study on Quaternary AlInGaN/GaN HFETs Grown on Sapphire Substrates. Semicond. Sci. Technol. 2010, 25, 75013. [CrossRef]

35. Schroder, D.K. Carrier and Doping Density. In Semiconductor Material and Device Characterization; John Wiley \& Sons, Inc.: Hoboken, NJ, USA, 2005; pp. 61-125.

36. Butté, R.; Carlin, J.-F.; Feltin, E.; Gonschorek, M.; Nicolay, S.; Christmann, G.; Simeonov, D.; Castiglia, A.; Dorsaz, J.; Buehlmann, H.J.; et al. Current Status of AlInN Layers Lattice-Matched to GaN for Photonics and Electronics. J. Phys. D Appl. Phys. 2007, 40, 6328-6344. [CrossRef]

37. Liuolia, V.; Marcinkevičius, S.; Billingsley, D.; Shatalov, M.; Yang, J.; Gaska, R.; Shur, M.S. Photoexcited Carrier Dynamics in AlInN/GaN Heterostructures. Appl. Phys. Lett. 2012, 100, 242104. [CrossRef]

38. Gonschorek, M.; Simeonov, D.; Carlin, J.-F.; Feltin, E.; Py, M.A.; Grandjean, N. Temperature Mapping of $\mathrm{Al}_{0.85} \mathrm{In}_{0.15} \mathrm{~N} / \mathrm{AlN} / \mathrm{GaN}$ High Electron Mobility Transistors through Micro-Photoluminescence Studies. Eur. Phys. J. Appl. Phys. 2009, 47, 30301. [CrossRef]

39. Marcinkevičius, S.; Liuolia, V.; Billingsley, D.; Shatalov, M.; Yang, J.; Gaska, R.; Shur, M.S. Transient Photoreflectance of AlInN/GaN Heterostructures. AIP Adv. 2012, 2, 042148. [CrossRef]

40. Marcinkevičius, S.; Sztein, A.; Nakamura, S.; Speck, J.S. Properties of Sub-Band Edge States in AlInN Studied by Time-Resolved Photoluminescence of a AlInN/GaN Heterostructure. Semicond. Sci. Technol. 2015, 30, 115017. [CrossRef]

41. Mouti, A.; Rouvière, J.-L.; Cantoni, M.; Carlin, J.-F.; Feltin, E.; Grandjean, N.; Stadelmann, P. Stress-Modulated Composition in the Vicinity of Dislocations in Nearly Lattice Matched $\mathrm{Al}_{\mathrm{x}} \mathrm{In}_{1-\mathrm{x}} \mathrm{N} / \mathrm{GaN}$ Heterostructures: A Possible Explanation of Defect Insensitivity. Phys. Rev. B 2011, 83, 195309. [CrossRef]

42. Schulz, S.; Caro, M.A.; Tan, L.-T.; Parbrook, P.J.; Martin, R.W.; O'Reilly, E.P. Composition-Dependent Band Gap and Band-Edge Bowing in AlInN: A Combined Theoretical and Experimental Study. Appl. Phys. Express 2013, 6, 121001. [CrossRef]

43. Wahab, Q.; Ellison, A.; Henry, A.; Janzén, E.; Hallin, C.; di Persio, J.; Martinez, R. Influence of Epitaxial Growth and SubstrateInduced Defects on the Breakdown of 4H-SiC Schottky Diodes. Appl. Phys. Lett. 2000, 76, 2725-2727. [CrossRef]

44. Muzykov, P.G.; Bolotnikov, A.V.; Sudarshan, T.S. Study of Leakage Current and Breakdown Issues in 4H-SiC Unterminated Schottky Diodes. Solid State Electron. 2009, 53, 14-17. [CrossRef]

45. Lee, K.-Y.; Capano, M.A. The Correlation of Surface Defects and Reverse Breakdown of 4H-SiC Schottky Barrier Diodes. J. Electron. Mater. 2007, 36, 272-276. [CrossRef]

46. Saito, W.; Kuraguchi, M.; Takada, Y.; Tsuda, K.; Omura, I.; Ogura, T. Influence of Surface Defect Charge at AlGaN-GaN-HEMT Upon Schottky Gate Leakage Current and Breakdown Voltage. IEEE Trans. Electron Devices 2005, 52, 159-164. [CrossRef]

47. Gaska, R.; Shur, M.S.; Hu, X.; Yang, J.W.; Tarakji, A.; Simin, G.; Khan, A.; Deng, J.; Werner, T.; Rumyantsev, S.; et al. Highly Doped Thin-Channel GaN-Metal-Semiconductor Field-Effect Transistors. Appl. Phys. Lett. 2001, 78, 769-771. [CrossRef] 